\title{
Material and decision flows in non-domestic building fit-outs
}

\author{
Miguel Casas-Arredondo*, Ben Croxford, Teresa Domenech \\ The Bartlett School of Environment, Energy and Resources, University College London, London, WC1E 6BT, United Kingdom
}

Keywords: Circular economy; Non-domestic building fit-outs; Interior refurbishment; Recycling; Material flow analysis (MFA).

\begin{abstract}
The built environment is the most resource intensive sector of the economy, accounting for a significant share of the extracted materials and the total waste generated. Within the built environment the most recurrent replacements of building materials and components take place during fit-outs, which are the process of installing interior fittings, fixtures and finishes. These materials and components are frequently replaced in non-domestic buildings.

Non-domestic building fit-outs are therefore responsible for a significant consumption of materials and a large source of waste. However, they tend to be excluded and unmeasured in the research on the built environment. The present work aims to study this research gap and analyse the potential for fit-outs to become more sustainable. The approach of this project ties in closely to the concept of circular economy, where materials are kept at their most useful state for as long as possible.

This paper analyses fit-out practices within London, identifying the supply-chain stakeholders, the key materials used and the waste streams generated, while tracing the decision and material flows across the supply chain. A material flow analysis (MFA) is conducted for a fit-out case study, showing the paths and destinations of the waste generated. The mixed methodology includes on-site observations, cross-examination of the corresponding waste reports, MFA, and qualitative analysis of interviews with the involved stakeholders.

The aim of this research is to provide a grounded perspective that allows the identification of process and design flaws as well as potential improvements that support the transition towards more "circular" fit-outs. It is concluded that there are potential areas of improvement as fit-out practices show a predominantly linear tendency both for decision making and material flows, in which there is a discontinuity of communication and material-flow information across the supply chain.
\end{abstract}

\section{Introduction}

The built environment is the most resource intensive sector of the economy, accounting annually in the European Union for $50 \%$ of all extracted materials, 35\% of carbon emissions (European Commission, 2011), and $32 \%$ of total waste generated, approximately 830 million tonnes (EEA, 2012). Within the built environment the most recurrent replacements of building materials and components take place during fit-outs, which are defined as the process of installing floor, wall and window coverings, partitions, doors, furniture, equipment, and sometimes mechanical and electrical services (Cole and Kernan, 1996; Forsythe, 2010). In non-domestic buildings these components can be replaced every 3-10 years (Trucker and Treloar, 1994; Roussac et al., 2008; Forsythe and Wilkinson, 2014). In addition, an outgoing tenant may remove the fit-out (de-fit) and the new tenant will reinstall all these fittings, fixtures, and finishes (re-fit). Accordingly, fit-outs account for a significant amount of wasted resources, and associated embodied carbon emissions throughout the lifecycle of a building.

Building fit-outs tend to go unnoticed and unmeasured in the debate about sustainable buildings (Forsythe and Wilkinson, 2014) but this is beginning to change. Building fit-out certification methods, such as SKA Rating (RICS, 2018), BREEAM (BRE, 2018a) or LEED (USGBC, 2018) exist, but have a low uptake (ECORYS, 2014) and do not fully cover the circular economy concept. Growing environmental concerns and the gradual increase of UK's landfill tax (Seely, 2009) certainly encourages stakeholders to pursue waste recycling instead of landfilling. However, most fit-out waste gets downcycled, since the original materials or components are generally not designed with recycling or reusing in mind (McDonough and Braungart, 1994).

In order to identify key areas of improvement in the fit-out process and in the use and management of resources, it is pertinent to understand the key materials used and waste generated, as well as the destinations of waste streams. 
This paper analyses non-domestic fit-out practices within University College London (UCL) and London, identifying the supply-chain stakeholders, the main materials used and waste streams generated, while tracing the decision and material flows across the supply chain. The objective of this work is to set a framework of characteristics of non-domestic building fit-outs and providing a more detailed explanation of a higher education institution (HEI) building fit-out, from a material flow perspective. The aim being to identify potential improvements in the fit-out process and the design of building components, reflecting on the possible benefits for main stakeholders involved and for society as a whole.

The following sections include the "Background" and the "Methodology", following on to present a "Common fit-out framework", in which secondary data obtained through interviews is used to present common characteristics of non-domestic fit-outs in the area. Next, a "HEl building fit-out case study" is closely analysed to show more specific attributes of a fit-out procedure, including a material flow analysis (MFA). Finally, findings are discussed and the paper concludes in the "Discussion and conclusions" section.

\section{Background}

Building fit-outs are a type of refurbishment, and the latter is defined as any building work that modifies the interior or exterior structure or aesthetic appearance of a building (RICS, 1997), normally with the aim to increase its social or economical value (RICS, 1973). In this context, the terms refurbishment and renovation are interchangeable (Lee, 1987) and these include modifications to the building such as retrofits (adding something to improve the building's performance (DBW, 2018)) and fit-outs (which relate to interior modifications).

Buildings can be seen and analysed in different layers, depending on function and replacement rate. Brand (1994) proposes six different layers: Site (geographical setting), Structure (load-bearing elements), Skin (building envelope), Services (cabling, plumbing, HVAC), Space plan (walls, partitions, ceiling, floor), and Stuff (furniture and equipment). These layers have increasing rates of replacement, from the Site being permanent to the Space plan and Stuff being replaced every three years or so. Fit-outs relate to the most frequently replaced layers: Services (sometimes), Space plan and Stuff. Brand (1994) demonstrates that in a 50-year cycle, the changes within a building cost three times more than the original building. Multiple authors state that the embodied energy of fit-outs eventually outweighs that used to construct the building (Cole and Kernan, 1996; Zabalza et al, 2009).

Non-domestic buildings, represent $26 \%$ of the total EU building stock per floor area, where $6 \%$ of the total are offices and $4 \%$ education buildings (Economidou, 2011). Non-domestic buildings may have 30 to 40 fit-outs during their lifecycle, accounting for an estimated $11 \%$ of UK construction spending (RICS, 2018).

The Construction Resources and Waste Platform (2009) carried out a study based on fit-out waste data contained in the SmartWaste (BRE, 2018b) tool. The average rate of waste generation is reported to be 6.4t per $100 \mathrm{~m}^{2}$ of gross internal floor area (GFA) for offices (based on four UK office fitout projects), $10.3 \mathrm{t}$ per $100 \mathrm{~m}^{2}$ of GFA for retail (based on six projects), and $33.7 \mathrm{t}$ per $100 \mathrm{~m}^{2}$ of GFA for education institution buildings (based on two projects). The reasons for the variability among types of space are not discussed.

The Better Building Partnership et al. (2015) used a fit-out case study in Sydney, Australia to record the types and amounts of waste generated. A rate of waste generation of close to $10 \mathrm{t}$ per $100 \mathrm{~m}^{2}$ of GFA was found, and $63 \%$ of this waste was diverted from landfill. The materials that were not able to be recycled were ceiling and carpet tiles, timbers, office furniture, and paint.

The Institute for Sustainable Futures (2014) performed a series of interviews in Sydney to identify the main waste contributors during fit-outs. The same few materials were consistently nominated: plasterboard, ceiling tiles, carpet, packaging, office furniture (particularly workstations) and the resultant MDF (medium-density fibreboard) and particleboard. It is stated that although some issues can be solved systematically, each material stream needs to be tackled specifically. 
Hardie et al. (2011) interviewed twenty-three experts in commercial refurbishments in Sydney to find out the average rate of reuse and recycling. They report that building materials and components such as aluminium, structural steel, steel reinforcing bars, bricks, and concrete, are subject to a high level of recycling, however, little recovery is made from the removal of most internal fittings and finishes during the fit-out process.

The findings of the present work were partly presented in a conference paper at PLATE 2017, in which a similar fit-out case study to the one included in this paper was used to carry out a material flow analysis (MFA), aiming to tie the fit-out process with the concept of circular economy (CasasArredondo et al., 2017).

Non-domestic building fit-outs generally represent the most recurrent refurbishment in the built environment and thus present an important opportunity to apply the principles of circular economy. The circular economy is a model proposed to replace the current 'take-make-dispose' scheme and to decouple environmental pressures from economic growth. The four sources of value creation in a circular economy to achieve this decoupling are (EMF, 2013): 1) minimising material use over a product's lifespan; 2) maximising the number of consecutive use cycles; 3 ) diversifying reuse across the value chain and across industries; and 4) using higher quality input materials. The term "circularity" is used in this work to reflect to what extent building materials or components keep their functional value either by being retained (in-situ), reused (onsite or offsite) or closed loop recycled.

There are current organisations or companies that support the transition towards more circular building fit-outs, acting as a sort of reuse intermediaries. Redistribution networks, such as Globechain (Globechain, 2018), Mobius-Reemploi (Mobius-reemploi, 2018), Rotor Deconstruction (RotorDC, 2018), or Warpit (Warpit, 2018) allow potential "re-users" to find reclaimed building components in order to reuse them in building projects.

\section{Methodology}

A mixed methodology approach is taken composed of specific methods to answer specific research questions. The research output contains a common framework of the non-domestic building fit-out process and an explanation of a HEI building fit-out case study, from a material flow perspective. Figure 1 shows a graphical representation of the methodological procedure. The research tasks were divided into three categories, as follows:

1) Mapping out the stakeholders within the fit-out supply chain who determine the specification of building components and the management of waste: exploratory interviews were conducted using chain-referral (snowball) sampling. Twelve people related to the fit-out industry were contacted and interviewed. The interview data was cross-checked to lead to an objective interpretation.

2) Describing the function of actors at each stage in the fit-out process and defining the relationships among them (evaluating their impact on the material flow): semi-structured interviews were carried out with the stakeholders identified in research objective 1. Three further fit-out experts were interviewed. The key aims in the interviews were to describe the fit-out process in-depth, to identify the roles and interactions of the supply-chain actors for each stage, and to define the main drivers and barriers to improved circularity in the fit-out process. The data from interviews and questionnaires was qualitatively analysed using NVivo.

3) Identifying the key material flows in fit-out projects: a) two Waste Contractors were interviewed and seven material recovery facilities (MRFs) were contacted. Also, b) a HEl building fit-out was selected as a case study to carry out a material flow analysis (MFA) of the waste streams generated during the project. The MFA was performed using data from stakeholders' reports, such as fit-out specifications, site waste management plans (SWMPs) and recycling reports. Also, site observations were carried out during and after fit-out. Lastly, c) a Sankey diagram was constructed for the case-study MFA using SankeyMATIC. 
Research objective

Identify potential improvements in the fit-out process and the design of building components

Methodological tool Research task

1)

Exploratory interviews using chain-referral sampling $\longrightarrow$ Map out stakeholders

within the fit-out supply chain

2)

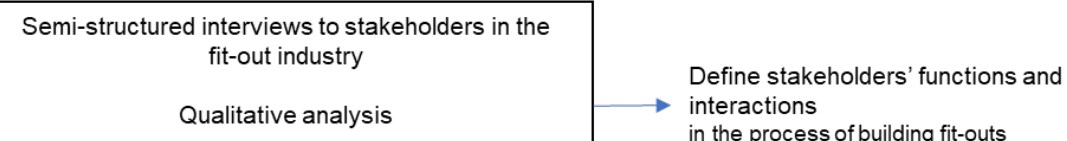

Semi-structured interviews to stakeholders in the fit-out industry

Qualitative analysis

Define stakeholders' functions and

interactions

)

in the process of building fit-outs

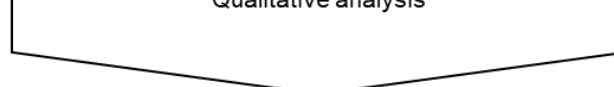

3a)

Structured interviews to Waste Contractors

Find key materials and wastes

in the non-domestic fit-out industry

3b)

On-site observations during fit-out works and analysis of logbook

Measure wastes generated

in a HEI building fit-out

Cross-examination of waste reports

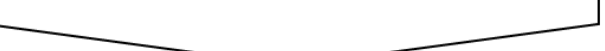

Structured interviews to Waste Contractors and

3c)

material recovery facilities (MRFs)

Material flow analysis (MFA)

Find paths and destinati

Research output

Common framework of non-domestic building fit-outs + Explanation of a HEl building fit-out case study, from a material flow perspective

Figure 1: Methodological procedure.

\section{Common fit-out framework}

\section{Common fit-out supply chain structure}

Several stakeholders within the non-domestic fit-out supply chain were interviewed including policy makers and stakeholders collaborating in the design team, as well as Fit-out Contractors, Waste Contractors and MRFs. From these interviews, it was concluded that fit-out processes encountered in the area of study are very similar to each other. Therefore, a common office and HEl fit-out supply chain is determined and described next.

Figure 2 shows the generic structure of the fit-out supply chain. The decision flow is represented in the diagram with an orange arrow and the material flow is represented with a green arrow. It can be appreciated that both the decision and the material flows have a linear tendency. 


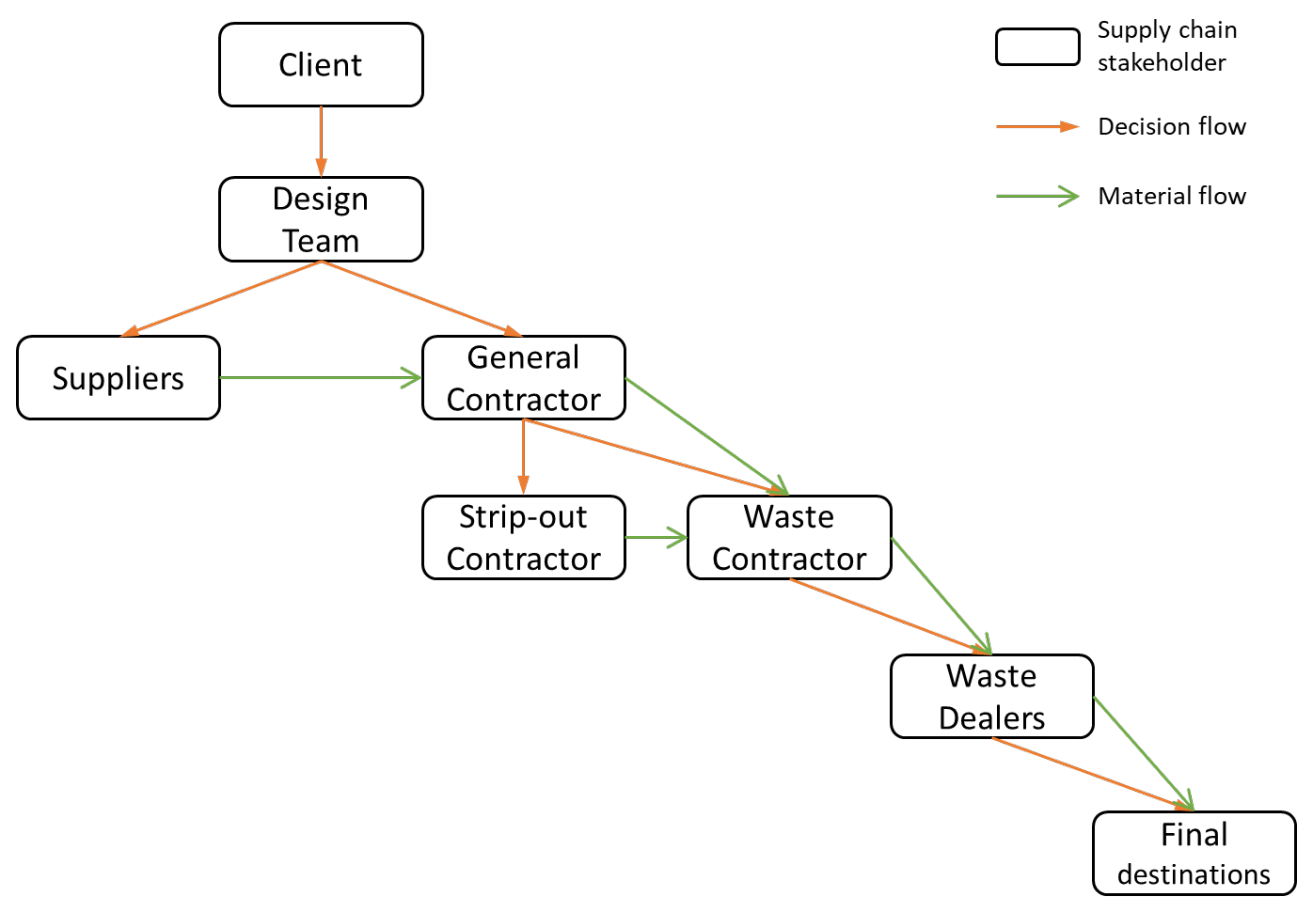

Figure 1: Common fit-out supply-chain stakeholders and structure.

The fit-out supply chain is generally formed in the following way: the Client decides to undertake a fitout, then choses the boundaries. They need to decide whether sustainability is a key requirement and what level is required, as well as whether to use an assessment method as guideline. The Client also hires the Design Team, which is usually comprised of an Architect, Project Manager(s), M\&E (Mechanical and Electrical) Engineer(s), Quantity Surveyor(s), and sometimes includes a Sustainability Consultant. The Design Team potentially has the highest impact on the decision making within the project, covering decisions such as the specification of building materials and components and the management of waste.

Once the project brief is developed by the Design Team (including project specifications, times and budget), the Project Manager sends out an invitation to tender. The invitation to tender (also known as Request for Tender) is commonly sent to prospective contractors (Select Tender), but can also take the form of an Open Tender which is done by public advertisement. Any Fit-out Contractor can then submit a tender, i.e. offer their services to carry out the fit-out works, stating how they would perform the job and how much it would cost. The tendering process should not be biased so the offer that best meets the requirements outlined in the Tender Package and provides the best value for money should get the contract. The Fit-out Contractor who gets the job, known thereafter as the General Contractor, will be in charge of all the on-site processes and they may sub-contract other actors, such as a Stripout Contractor (also known as Demolition Contractor) or a Waste Contractor. Likewise, the General Contractor normally has within their team another Project Manager, M\&E Engineer, Quantity Surveyor and a Sustainability Manager.

The Waste Contractor assigned by the General Contractor will be in charge of collecting the waste arising from the de-fit (demolition) and re-fit (installation) stages to then take it to a transfer site, where waste usually gets sorted into different waste streams. In some instances, the Strip-out Contractor may assign a different Waste Contractor for the de-fit process, or the Strip-out Contractor may take care of the waste themselves if they have a waste-carrier license.

The different waste streams are then sent out to different MRFs or Waste dealers where each waste stream is aggregated. Each MRF may deal with one or several different waste streams. The respective Waste dealers further sort and grade the waste streams for onward delivery, potentially to their respective final destinations. These destinations may include recycling within the original industry (closed-loop) or in another industry, as well as incineration for energy recovery or landfill. 
In terms of material flow, the Suppliers produce and market the building products, and the Design Team selects from the available offer. The General and Strip-out contractors install and remove the products, respectively. The Waste Contractor collects the waste and sorts it, to then hand over the different waste streams to the corresponding Waste dealers who further sort and grade the waste before sending it to the respective final destinations.

During this study, it was found that the Design Team and the General/Strip-out Contractor generally have negligible knowledge about the final destinations of components and materials, whereas the Waste Contractors and the people in charge of the final destinations generally have insignificant influence on the specification of these components. It can be suggested that the linear tendency of the decision flow is a barrier for the circularity of the material flow.

\section{Common fit-out materials and components}

Table 1 and 2 present a list of the common fit-out materials and components, respectively, along with the corresponding European Waste Code (EWC), where available. These materials and components are consistently considered in the literature review and in fit-out SWMPs. The components shown in Table 2 are manufactured products composed of more than one material.

Out of these materials and components, there are some deemed as hazardous waste (asbestos, paint and adhesives, fluorescent lamps, WEEE), while hardcore is considered to be inert and entails a lower landfill tax. Gypsum-based products are required to be closed-loop recycled or landfilled in a separate cell away from biodegradable waste to avoid the production of hydrogen sulphide (UK Government, 2018). Mixed waste is technically not a waste stream as it is composed of various materials and components, but it is included in Table 1 in order to be comprehensive.

Table 1: Common fit-out materials (Author generated, 2017).

\begin{tabular}{|l|c|c|}
\hline \multicolumn{3}{|c|}{ M A T E R I A L S } \\
\hline Element & EWC & Waste stream \\
\hline Ceramics & 170605 & asbestos \\
\hline Glass & 170103 & hardcore \\
\hline Gypsum (including plasterboard) & 170202 & glass \\
\hline Hardcore & 170802 & gypsum \\
\hline Insulation & 170107 & hardcore \\
\hline Metals -Ferrous & 170604 & varies \\
\hline Metals -Non-ferrous & 170405 & metals \\
\hline Mixed waste & $170401 *$ & metals \\
\hline Paint, adhesive, etc. & 170904 & mixed waste \\
\hline Paper \& Cardboard & 200127 & hazardous \\
\hline Plastics (including packaging) & 200101 & paper \\
\hline Textiles & 170203 & plastics \\
\hline Wood (including fibreboard) & 200111 & textiles $\|$ mixed waste \\
\hline \multicolumn{2}{|c|}{ Symbols: } & $\|$ means OR \\
\hline
\end{tabular}

* Non-ferrous metals also include EWCs 1704 02, 1704 03, 170404 and 170406.

Table 2: Common fit-out components (Author generated, 2017).

\begin{tabular}{|l|c|c|}
\hline \multicolumn{3}{|c|}{ C O M P O N E N T S } \\
\hline \multicolumn{1}{|c|}{ Element } & EWC & Waste stream \\
\hline Carpet/carpet tiles & N/A & textiles \| mixed waste \\
\hline Doors & N/A & glass \| metals \| plastics I| wood \\
\hline Ductwork & N/A & metals \\
\hline
\end{tabular}




\begin{tabular}{|l|c|c|}
\hline Electrical socket & N/A & metals \& plastics \\
\hline Fluorescent lamps & 200121 & glass \& metals \& mercury \\
\hline Light fittings & N/A & metals \& plastics \\
\hline Office furniture & N/A & varies \\
\hline Resilient flooring & N/A & varies \\
\hline Raised access floor & N/A & metal \& wood \| hardcore \\
\hline Suspended ceiling tiles & N/A & mixed waste \\
\hline WEEE & 20 01 36 & WEEE \\
\hline \multicolumn{2}{|c|}{ Symbols: $\quad$ \& means AND, \| means OR } \\
\hline
\end{tabular}

\section{Common fit-out waste generation}

Building fit-out materials and components are generally considered to be waste, and treated as such, once they are removed from the building site. The umbrella of building materials and components are categorised into a few waste streams in order to be segregated and treated. A major Waste Contractor in London was contacted in order to find out the top waste streams generated during fit-out projects (Table 3). Over $90 \%$ of the waste they collect comes from building fit-outs. Figure 2 shows the share or percentage (by weight) for each material stream relative to the overall waste collection, for the first quarter of 2017. Gypsum (including plasterboard) accounts for the largest share, followed by mixed waste, metals, wood (including fibreboard and particleboard), glass, hardcore, paper \& cardboard, WEEE, and fluorescent lamps.

Table 3: Weight and share for each material stream collected, for the first quarter of 2017 (Waste Contractor's report, 2017).

\begin{tabular}{|c|c|c|c|}
\hline Waste stream & EWC & Weight [t] & Share [\%] \\
\hline Gypsum (including plasterboard) & 170802 & 72.59 & 31.8 \\
\hline Mixed waste & 170904 & 66.25 & 29.0 \\
\hline Metals & $170401^{*}$ & 32.84 & 14.4 \\
\hline Wood (including fibreboard) & 170201 & 25.06 & 11.0 \\
\hline Glass & 170202 & 13.02 & 5.7 \\
\hline Hardcore & 170107 & 11.90 & 5.2 \\
\hline Paper \& Cardboard & 200101 & 6.18 & 2.7 \\
\hline WEEE & 200136 & 0.32 & 0.1 \\
\hline Fluorescent lamps & 200121 & 0.30 & 0.1 \\
\hline TOTAL & & 228.46 & 100.0 \\
\hline
\end{tabular}

* Metals also include EWCs 170402 to 170406.

\section{HEI building fit-out case study}

Four non-domestic building fit-outs were analysed during this work in order to quantify and trace the material flow during the fit-out process. A higher education institution (HEI) building fit-out was selected as case study and is presented below. The fit-out project aimed to turn formerly unused space into multi-use space for the teaching of Chinese language and culture, as part of the UCL Institute of Education. The Confucius Institute fit-out took place between December 2016 and June 2017 , with a project value of $£ 866 \mathrm{k}$, and was certified as SKA Gold using the Office Scheme. The 1847 building is located in Bloomsbury and belongs to UCL Estates. The building comprises four stories plus a basement, which result in a gross floor area (GFA) of $290 \mathrm{~m}^{2}$.

The information presented in this section was provided (and cross-checked) by the Client's (UCL) Sustainability Officer (personal interview, 24 November 2016 and 03 May 2017), the General 
Contractor's Site Manager (personal interview, 24 November 2016, 09 December 2016 and 11 April 2017) and the Waste Contractor's Senior Sustainability Manager (personal interview, 21 October 2016; personal communication 05 June 2017).

\section{Case-study supply chain structure}

Figure 3 shows the supply-chain stakeholders and structure. The Client was represented by a UCL Stakeholder, a UCL Project Manager and the UCL Sustainability Officer. The Client assigned a Design Team to be in charge of the whole project design which was compiled in the Tender Package. The Design Team comprised actors from different firms respectively; namely, a Project Manager (also known as External Project Manager), an Architect, a M\&E Consultant, and a Quantity Surveyor. The Design Team appointed a General Contractor to be in charge of the works on site, and the General Contractor, in turn, appointed a Strip-out Contractor to carry out the de-fit stage. The Suppliers were selected by both the Design Team and the General Contractor, as some building components and materials were specified by the Design Team and the General Contractor changed some of the specified components and added new ones. The Waste Contractor, which was subcontracted by the General Contractor, was used for both the de-fit and re-fit stages. However, the Strip-out Contractor hired a waste carrier in order to deliver the de-fit waste to the Waste Contractor's transfer site, while the re-fit waste was collected by the Waste Contractor themselves. The Waste Contractors determined different Waste dealers for different waste streams. Finally, the respective final destinations were established by the Waste dealers.

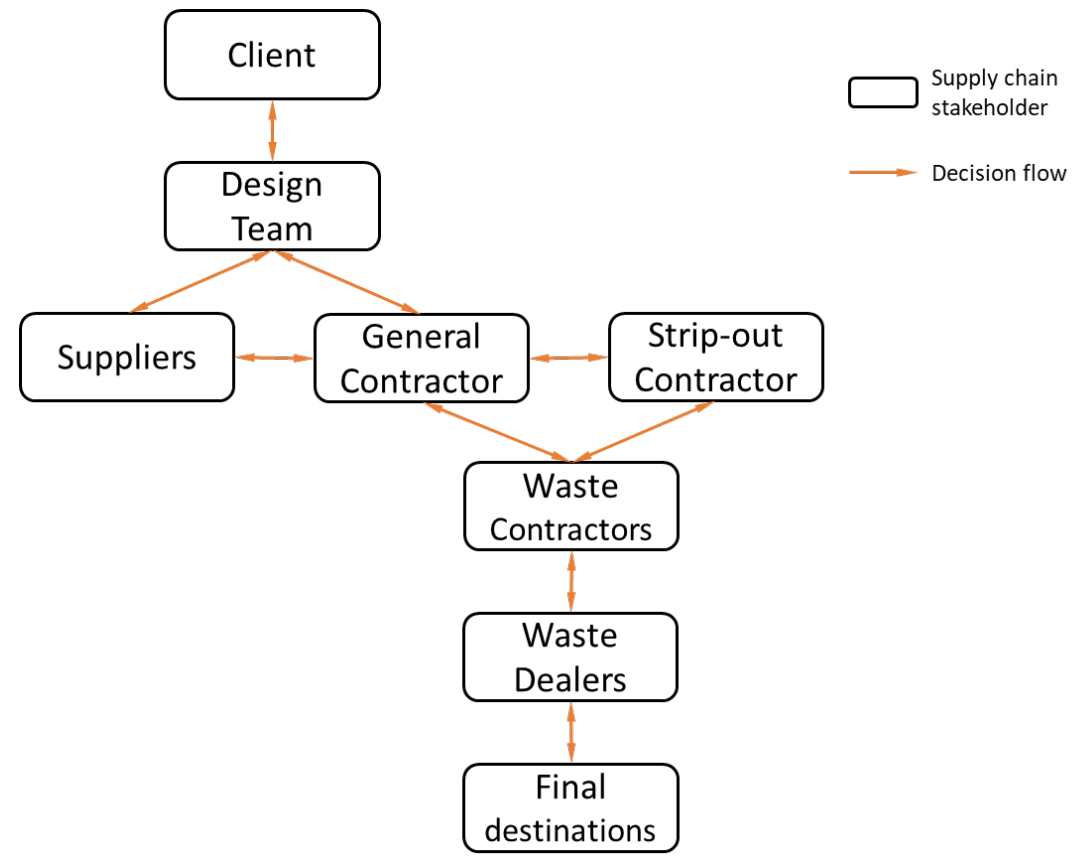

Figure 3: Supply-chain structure showing the decision flow, for UCL Confucius Institute (personal interviews, 2016).

In terms of decision flow among supply-chain stakeholders, it was recognised that the communication mainly took place between the adjacent stakeholders (as seen in Figure 3), but there was no effective communication among nonadjacent actors. When interviewed, the General Contractor's Site Manager said he was unaware of the potential final destinations of waste streams generated during the fit-out process. The General Contractor's Environmental and Sustainability Manager (personal interview, 27 September 2016) said at an earlier interview that he had no certainty about what becomes of the fitout waste but he believed that most waste streams get downcycled.

When the Waste Contractor's Senior Sustainability Manager was interviewed, a similar response was provided. On the other hand, he said Waste Contractors are commonly not taken into account, in the design stage or for the decision making at the fit-out process, although they could advice and support 
on issues such as pre-refurbishment audit, potential component reuse, waste segregation, and takeback schemes.

In the same way as the decision flow, the material flow for this case study shows a predominantly linear tendency. Figure 4 shows the path followed by the material/waste throughout the different locations within the supply chain. Materials and components were firstly provided by suppliers and taken to the building site where they are installed and subsequently removed. When these materials and components got removed, they were considered and treated as waste so they were taken to a waste transfer site to be segregated. After segregation, different waste streams were taken to the corresponding MRFs before being sent to the corresponding final destinations.

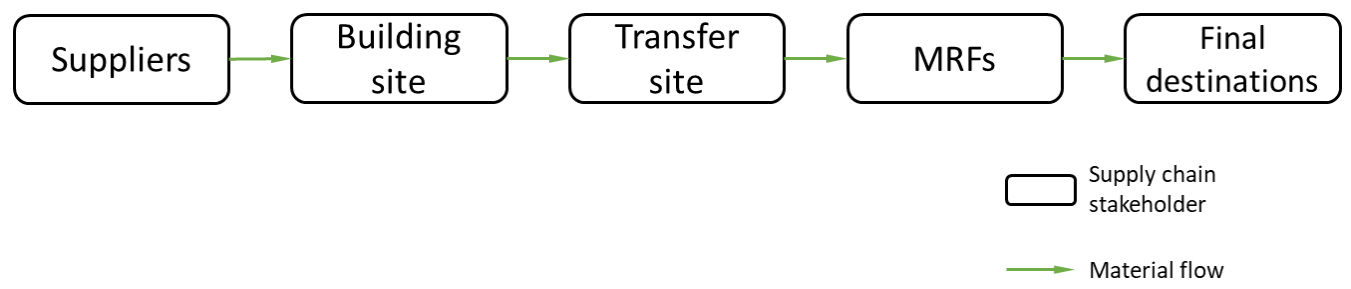

Figure 4: Material flow across the corresponding locations, for UCL Confucius Institute (personal interviews, 2016).

\section{Case-study waste generation}

The total waste generated during this fit-out project was $35.28 \mathrm{t}$, including $12.18 \mathrm{t}$ for the de-fit stage, with a landfill diversion rate of $75 \%$, and $23.10 \mathrm{t}$ for the re-fit stage, where the reported landfill diversion rate was $99 \%$. The average landfill diversion rate considering both stages was $91 \%$, while the rate of waste generation was $12.17 \mathrm{t}$ per $100 \mathrm{~m}^{2}$ of GFA.

Table 4 shows a breakdown of the waste streams generated during the de-fit stage. Waste during this stage accounts for $35 \%$ of the total waste generated. Table 5 shows the waste-stream breakdown for the re-fit stage, which accounts for $65 \%$ of the total waste. Lastly, Table 6 presents the waste-stream breakdown combined for both the de-fit and re-fit stages.

Table 4: Waste generated during de-fit at UCL Confucius Institute (fit-out SWMP, 2017).

\begin{tabular}{|l|c|c|c|}
\hline \multicolumn{4}{|c|}{ De-fit waste } \\
\hline \multicolumn{1}{|c|}{ Item } & $\begin{array}{c}\text { Weight } \\
\text { [t] }\end{array}$ & $\begin{array}{c}\text { Recycled } \\
{[\mathbf{t}]}\end{array}$ & $\begin{array}{c}\text { Disposed } \\
{[\mathbf{t}]}\end{array}$ \\
\hline Asbestos & 0.49 & 0.00 & 0.49 \\
\hline Glass & 0.37 & 0.37 & 0.00 \\
\hline Hardcore & 4.00 & 4.00 & 0.00 \\
\hline Mixed waste & 7.32 & 4.76 & 2.56 \\
\hline Total [t] & $\mathbf{1 2 . 1 8}$ & $\mathbf{9 . 1 3}$ & $\mathbf{3 . 0 5}$ \\
\hline Percentage [\%] & $\mathbf{1 0 0}$ & $\mathbf{7 5 . 0}$ & $\mathbf{2 5 . 0}$ \\
\hline
\end{tabular}

Table 5: Waste generated during re-fit at UCL Confucius Institute (fit-out SWMP, 2017).

\begin{tabular}{|l|c|c|c|}
\hline \multicolumn{4}{|c|}{ Re-fit waste } \\
\hline \multicolumn{1}{|c|}{ Item } & $\begin{array}{c}\text { Weight } \\
{[\mathrm{t}]}\end{array}$ & $\begin{array}{c}\text { Recycled } \\
{[\mathrm{t}]}\end{array}$ & $\begin{array}{c}\text { Disposed } \\
{[\mathrm{t}]}\end{array}$ \\
\hline Hardcore & 5.47 & 5.47 & 0.00 \\
\hline Glass & 1.02 & 1.02 & 0.00 \\
\hline Metals & 2.49 & 2.49 & 0.00 \\
\hline Plasterboard & 2.50 & 2.50 & 0.00 \\
\hline
\end{tabular}




\begin{tabular}{|l|c|c|c|} 
Plastics & 1.61 & 1.61 & 0.00 \\
\hline Textiles & 2.65 & 2.52 & 0.13 \\
\hline Wood & 7.36 & 7.36 & 0.00 \\
\hline Total [t] & $\mathbf{2 3 . 1 0}$ & $\mathbf{2 2 . 9 7}$ & $\mathbf{0 . 1 3}$ \\
\hline Percentage [\%] & $\mathbf{1 0 0}$ & $\mathbf{9 9 . 4}$ & $\mathbf{0 . 6}$ \\
\hline
\end{tabular}

Table 6: Waste generated during de-fit and re-fit at UCL Confucius Institute (fit-out SWMP, 2017).

\begin{tabular}{|l|c|c|c|}
\hline \multicolumn{4}{|c|}{ All waste } \\
\hline \multicolumn{1}{|c|}{ Item } & $\begin{array}{c}\text { Weight } \\
\text { [t] }\end{array}$ & $\begin{array}{c}\text { Recycled } \\
{[\mathbf{t}]}\end{array}$ & $\begin{array}{c}\text { Disposed } \\
{[\mathbf{t}]}\end{array}$ \\
\hline Asbestos & 0.49 & 0.00 & 0.49 \\
\hline Hardcore & 9.47 & 9.47 & 0.00 \\
\hline Mixed waste & 7.32 & 4.76 & 2.56 \\
\hline Glass & 1.39 & 1.39 & 0.00 \\
\hline Metals & 2.49 & 2.49 & 0.00 \\
\hline Plasterboard & 2.50 & 2.50 & 0.00 \\
\hline Plastics & 1.61 & 1.61 & 0.00 \\
\hline Textiles & 2.65 & 2.51 & 0.14 \\
\hline Wood & 7.36 & 7.36 & 0.00 \\
\hline Total [t] & $\mathbf{3 5 . 2 8}$ & $\mathbf{3 2 . 0 9}$ & $\mathbf{3 . 1 9}$ \\
\hline Percentage [\%] & $\mathbf{1 0 0}$ & $\mathbf{9 1 . 0}$ & $\mathbf{9 . 0}$ \\
\hline
\end{tabular}

Figure 5 presents a bar chart showing the percentages or shares (by weight) of each waste stream relative to the overall waste collection. For this case study, hardcore accounts for the largest share $(27 \%)$, followed by wood -including fibreboard- $(21 \%)$, mixed waste $(21 \%)$, textiles -including carpet tiles- $(8 \%)$, gypsum -mainly plasterboard- $(7 \%)$, metals $(7 \%)$, plastics $(5 \%)$, glass $(4 \%)$, and asbestos $(1 \%)$.

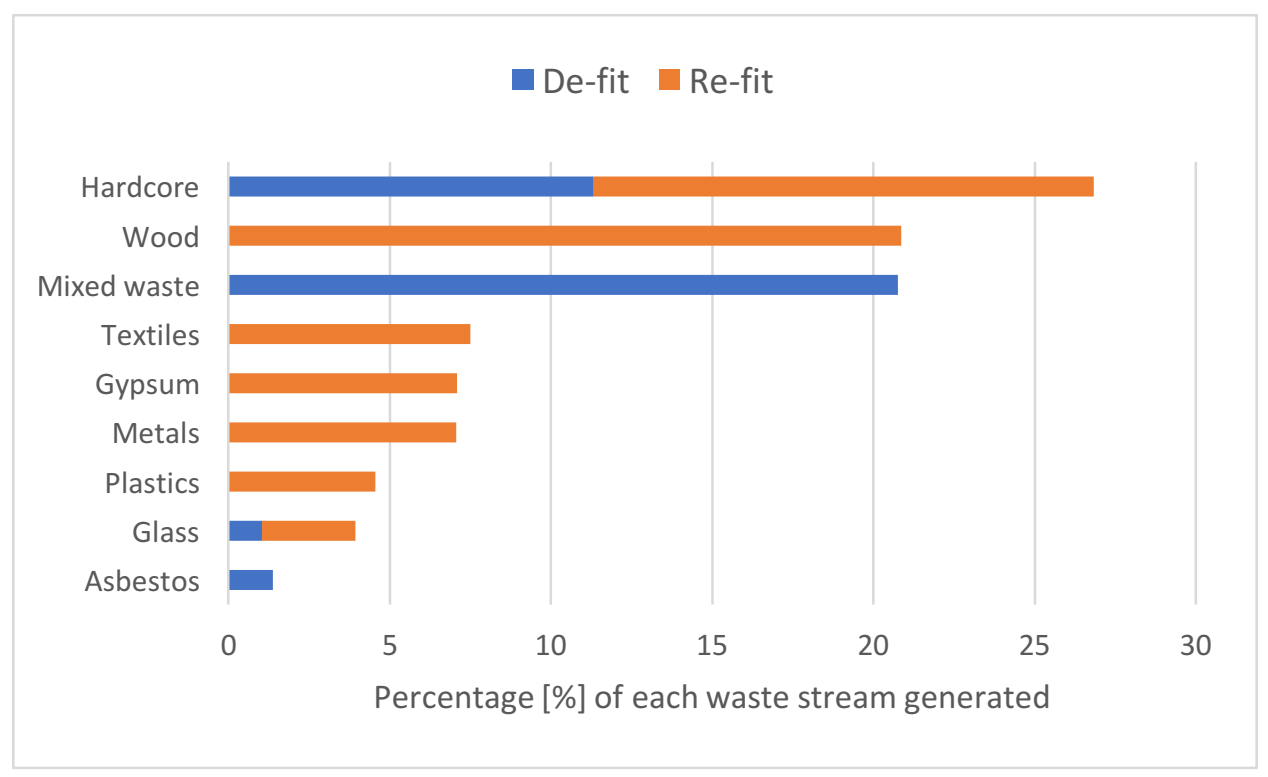

Figure 5: Percentage (by weight) for each waste stream relative to the overall waste generation, for UCL Confucius Institute fit-out (fit-out SWMP, 2017). 
It should be noted that building components removed during this fit-out project were considered waste and categorised into the respective waste stream as soon as they were removed, thus decreasing their functional value. However, there are many components in good condition that could have been retained or reused, saving the energy and $\mathrm{CO}_{2}$ emissions embodied in the new components. When interviewed, the General Contractor's Site Manager claimed that offsite reuse of components was negligible due to the lack of a market for reused building components. Accordingly, some components were disposed of despite being in good or excellent condition, such as: $218 \mathrm{~m}^{2}$ of carpet tiles and the plywood layer underneath, 30 light fittings, 64 fluorescent lamps, 115 wooden shelves, and 70 electrical sockets, among others. These building components were taken by the Waste Contractor in order to be presumably recycled. The next section presents the paths and final destinations of the waste streams generated during the fit-out project.

\section{Case-study waste stream destinations}

The General Contractor (and the upstream stakeholders) tend to sub-contract a Waste Contractor that can ensure a high rate of landfill diversion. This is generally driven by environmental reasons whether or not a certification or assessment method is followed.

Another important reason for landfill diversion is the gradual increase of landfill tax, as handing the waste to a Waste Contractor is normally cheaper than landfilling. The 'gate fee' in this context refers to the price that the Waste Contractor charges per tonne for each waste stream collected. For this case study, the highest gate fee was charged for mixed waste, followed by plasterboard, and wood. Hardcore was collected free of charge, while other waste streams were even paid for, such as metals, paper \& cardboard, and plastics.

Figure 6 shows the flow of the respective waste streams across the supply chain for the fit-out case study. Each waste stream is represented by a different colour - a change of colour at the end means the waste stream has been converted into something else. Although $91 \%$ of the waste was reported as recycled, the final destinations include other recovery alternatives such as composting $(0.5 t)$ and incineration (2.21t). Recycled waste streams diversify into multiple recycling destinations that require a lower grade of material quality, with the exception of $60 \%$ of the gypsum, which was turned into new plasterboard. Therefore, only $4 \%$ (1.5t) of material was closed-loop recycled out of $35.28 \mathrm{t}$ of waste generated during the fit-out process. Gypsum was the only waste stream that showed some percentage of closed-loop recycling, driven by UK regulations which estipulate a special treatment for gypsum-based products. About $8 \%(2.7 \mathrm{t})$ of the total waste was landfilled, while asbestos $(0.49 \mathrm{t})$ were collected by a specialised contractor and sent to deep landfill burial.

In this case, wood was sent to Belgium, metals ended up in Spain or Turkey (or other countries depending on the offered price at the time), and plastics were sent to China, while all other final destinations are located within the UK. In total, around $41 \%$ (14.64t) of waste was exported abroad. 


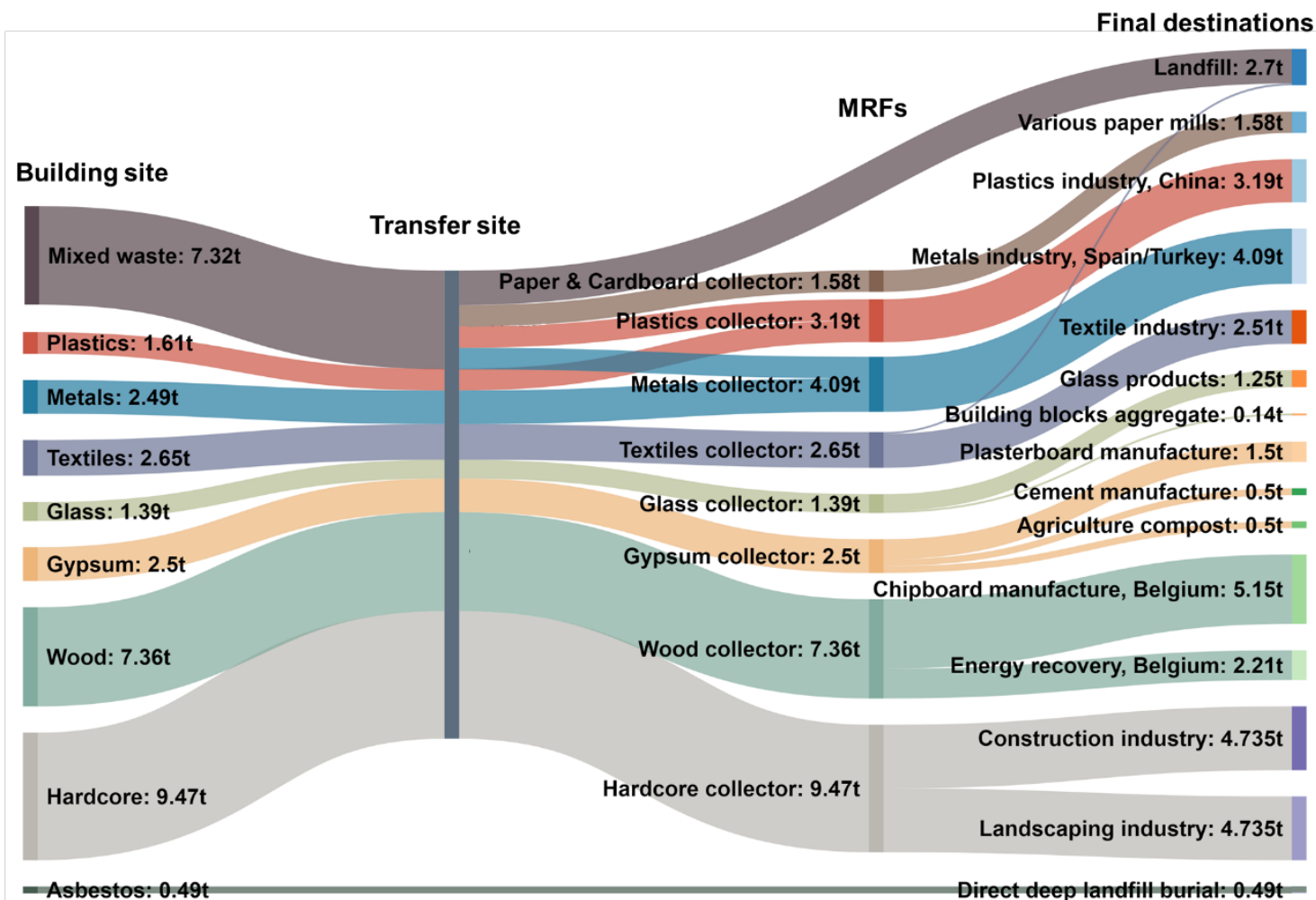

Figure 6: Waste-stream flows in tonnes for a $290 \mathrm{~m}^{2}$ HEI building fit-out, out of $35.28 \mathrm{t}$ of waste.

\section{Discussion and conclusions}

Given the qualitative and quantitative analysis of non-domestic building fit-outs, it is clear there are several areas that can be improved. It was found that the supply chain for office and higher education institution (HEI) building fit-outs has a generic structure in which both decision and material flows show a predominantly linear tendency. The stakeholders in this supply chain with the highest impact on the specification of materials and components and the decision making on waste management are generally the client and the design team, while there is a discontinuity of communication and information across the supply chain.

Currently, good-practice fit-out projects (and the corresponding assessment methods) pursue high recycling percentages for the generated waste streams. However, this study found that the stakeholders in the supply chain are generally unaware of the waste streams' final destinations, i.e. what the different waste streams get recycled into or used for. In the fit-out case study it was found that only $4 \%(1.50 \mathrm{t})$ of material was closed-loop recycled out of $35.28 \mathrm{t}$ of waste generated during the fit-out process. The remaining waste was downcycled, while $2.21 \mathrm{t}$ were incinerated (for energy recovery), and $0.50 t$ were used as compost. Out of the total, $42 \%$ (14.64t) of waste was exported abroad and the rest was treated within the UK. Waste final destinations were determined by market (prices) rather than environmental criteria.

The final destinations of building products are generally unclear as there is not enough evidence to ascertain what exactly happens to most material and components until they become something else. The main reason of this ambiguity is found to be the reduction of information across the supply chain. Waste is given to the Waste Contractor, who in turn provides a waste report claiming the waste will be recycled at a given rate (e.g. $91 \%$ ). The issued waste report serves as a measure for the recycling rate within a building process, or as evidence for an assessment method or certification scheme. However, neither the client, the certification schemes nor the government require data or evidence on the actual final destinations of the waste generated during fit-out processes. The waste path and the involved downstream supply chain are practically disconnected from the building process and its direct stakeholders in terms of communication and information. 
During this research, there has been some reluctance from waste handlers to provide data on waste final destinations as this is deemed as commercially sensitive information. Moreover, data bases such as Eurostat (Eurostat, 2018) do not provide information about recycling output, and the Environment Agency (Environment Agency, 2018) is not implementing strict auditing and standards on the final destinations of waste streams. Likewise, the material losses in the segregation and recycling process are not considered or reported. As the Sustainability Manager from the interviewed Waste Contractor stated: "without a standard how can you know they [the waste handlers] do what they say they do?".

Therefore, better mechanisms are needed to elucidate the whole path of end-of-life building products until they become something else. This feedback is important to better understand the paths of waste products and therefore be able to improve the circular performance. As well, it is pertinent to improve assessment methods or certification schemes so that these take into account building processes from a circular approach. Normally, rating systems assess the sustainability of waste management in terms of recycling rates, but require no evidence on how, where, or what the waste is recycled into. For instance, a PVC window recycled into another PVC building product by a local recycling site, is likely to be more sustainable than the window being transported a long distance (e.g. to China) and going into an uncertain recycling process.

The top-five waste streams generated during the fit-out case study were hardcore, mixed waste, wood, plastics and metals. The top waste streams collected during a three-month period by the interviewed waste contractor were gypsum, mixed waste, metals, wood, and glass. In both cases, mixed waste accounted for a significant share, even though the gate fee for mixed waste is generally the highest compared to other waste streams. It is advisable for the General/Strip-out Contractor to segregate waste on site, and in fact, some segregated waste streams are collected free of charge or even paid for. It should be noted that waste from fit-outs gets recorded using European Waste Codes (EWCs) but these do not reveal which building materials and components the waste streams relate to.

The rate of waste generation (RWG) in the case-study fit-out was $12.17 \mathrm{t}$ per $100 \mathrm{~m}^{2}$ of gross internal floor area (GFA). This is higher than the reported average for offices of $6.4 \mathrm{t}$ per $100 \mathrm{~m}^{2}$ of GFA, but lower than the average for HEl buildings of $33.7 \mathrm{t}$ per $100 \mathrm{~m}^{2}$ of GFA. There are other indicators such as ' $\mathrm{m}^{3}$ of waste per $100 \mathrm{~m}^{2}$ of GFA', ' $\mathrm{m}^{3}$ of waste per $£ 100 \mathrm{k}$ of project value', and 'tonnes of waste per $£ 100 \mathrm{k}$ of project value' (CRW, 2009). The most widely used RWG indicator is 'tonnes of waste per $100 \mathrm{~m}^{2}$ of GFA', which is the one used in this study, however there is no standardisation and there is some subjectivity to it.

This RWG can reflect the sustainability and efficiency of the resource management during the refurbishment process. RWG depends of the design of the fit-out process and outcome, but it also depends on the amount of materials and components installed in the building before fit-out, which is a pre-existing condition. Therefore, the amount of pre-installed items on site affects the RWG but it is not intrinsic to the fit-out process and does not necessarily reflect on the quality of the resource management during the process, which makes this indicator subjective. Furthermore, there are heavier materials whose weight do not correlate with their environmental burden. For instance, concrete is heavier than insulation, but insulation generally presents higher environmental impacts, so having a tonne of insulation means higher environmental concerns than a tonne of concrete. Certification schemes like SKA Rating, BREEAM or LEED do not properly differ between the relative environmental impact of each type of material.

There are two different "circular" paths regarding fit-out resources. The path of closed-loop recycling on one hand, and the path of reuse on the other end. Each of these paths require a different approach and entail different criteria to make them work. For instance, closed-loop recycling requires a reverselogistic scheme which support the circular cycle and also requires product materials that are pure enough or can be properly separated to be recycled. Reuse is rather related to issues such as size standardisation, modularity, product lifespans and availability of a reuse market. Better sharing/reuse platforms are needed so more reuse can happen - maybe a national sharing platform. Issues such as time, space and transport are crucial for the efficient implementation of reuse or close-loop recycling, and therefore, logistics result to be the common ground for both paths. 
The findings and conclusions presented in this work are transferable to some extent to other types of non-domestic buildings, such as retail, hotels, restaurants and healthcare. In this context, the similarities among non-domestic buildings include: rate of replacement of interior materials and components (to some extent), design criteria of components in order to make them modular, reusable and recyclable, supply-chain scale, structure and trends, types of waste streams and their treatment, and the assessment methods used. On the other hand, some particular components differ (e.g. display cabinets in retail buildings) and the different use of the space may require additional considerations.

\title{
Scope and future work
}

The findings of this work are based on a set of interviewed stakeholders and involvement in four fitout case studies - although only one case study is presented here. The study does not cover a comprehensive sample of the UCL building portfolio or fit-out practices in London. However, some findings of this work are transferable to the non-domestic fit-out industry.

The methodological approach encountered some barriers as several stakeholders were reluctant to participate or provide concise information. This work disregards critical materials which are contained in components such as fluorescent lamps and WEEE.

Future work should consider critical materials and the financial value of material flows. This paper is presented with the expectation that a life-cycle analysis (LCA) would be conducted to assess the full environmental impact and identifying hotspots.

\section{Acknowledgments}

The authors acknowledge the support and the data provided by the interviewees and the corresponding stakeholders. The authors also thank the reviewers and the editors for their helpful comments. Finally, Miguel Casas-Arredondo acknowledges scholarship grant 324656 by CONACYT.

\author{
Abbreviations \\ EU: European Union \\ EWC: European Waste Code \\ GFA: Gross Floor Area \\ HEl: Higher Education Institution \\ HVAC: Heating, Ventilating and Air-Conditioning \\ LCA: Life-cycle Analysis/Assessment \\ LEED: Leader in Energy and Environmental Design \\ MDF: Medium-Density Fibreboard \\ MFA: Material Flow Analysis \\ MRF: Material Recovery Facility \\ M\&E: Mechanical and Electrical \\ PVC: Polyvinyl Chloride \\ RWG: Rate of Waste Generation \\ SWMP: Site Waste Management Plan \\ UCL: University College London \\ WEEE: Waste Electrical and Electronic Equipment
}

BREEAM: Building Research Establishment Environmental Assessment Method

\section{References}

BBP (Better Building Partnership), Dexus and Edge Environment, 2015. Case study in resource recovery from office strip out: Governor Macquarie Tower. Australia.

BRE (Building Research Establishment), 2018a. BREEAM's (Building Research Establishment Environmental Assessment Method) Official Website [online]. Retrieved from: https://www.breeam.com/ [Accessed 21 August 2018]. 
BRE (Building Research Establishment), 2018b. SmartWaste's Official Website [online]. Retrieved from: https://www.bresmartsite.com/products/smartwaste/ [Accessed 24 August 2018].

Brand, S., 1994. How buildings learn. What happens after they're built. $2^{\text {nd }}$ ed. London, UK: Phoenix Illustrated.

Casas-Arredondo, M., Croxford, B. and Domenech, T., 2017. Towards more circular office fit-outs: a sociotechnical descriptive framework of office fit-out processes. In: C. Bakker and R. Mugge, PLATE: Products Lifetimes and The Environment [online]. Delft, Netherlands: Open Access, 70-75. Retrieved from: http://ebooks.iospress.nl/volumearticle/47845 [Accessed 24 August 2018].

Cole, R.J. and Kernan, P.C., 1996. Life-cycle energy use in office buildings. Building and Environment, 31 (4): 307-317. DOI: 10.1016/0360-1323(96)00017-0

CRW (Construction Resources \& Waste Platform), 2009. Refurbishment Waste Benchmarking Report [online]. UK. Retrieved from: http://www.wrap.org.uk/sites/files/wrap/Refurbishment-waste-benchmarking-report.pdf [Accessed 14 June 2017].

DBW (Designing Buildings Wiki), 2018. Retrofit [online]. Retrieved from: https://www.designingbuildings.co.uk/wiki/Retrofit [Accessed 22 August 2018].

Economidou, M., 2011. Europe's buildings under the microscope - A country-by-country review of the energy performance of buildings [online]. Building Performance Institute Europe. Retrieved from: http://www.europeanclimate.org/documents/LR_\%20CbC_study.pdf [Accessed 22 December 2015].

ECORYS, 2014. Resource efficiency in the building sector. Final Report [online]. Rotterdam. Retrieved from: http://ec.europa.eu/environment/eussd/pdf/Resource\%20efficiency\%20in\%20the\%20building\%20sector.pdf [Accessed 18 December 2016].

EEA (European Environment Agency), 2012. Material resources and waste - 2012 Update. The European Environment, State and Outlook 2010. Copenhagen, Denmark.

EMF (ELLEN MACARTHUR FOUNDATION), 2013. Towards a Circular Economy: Business rationale for an accelerated transition [online]. Retrieved from:

http://www.ellenmacarthurfoundation.org/assets/downloads/TCE_Ellen-MacArthur-Foundation_9-Dec-2015.pdf [Accessed 22 December 2015].

Environment Agency, 2018. Environment Agency's Official Website [online]. Retrieved from: https://www.gov.uk/government/organisations/environment-agency [Accessed 12 March 2018].

European Commission, 2011. Communication from the Commission to the European Parliament, the Council, the European Economic and Social Committee and the Committee of the Regions: Roadmap to Resource Efficient Europe, COM (2011) 571 final. Brussels, Belgium.

Eurostat, 2018. Eurostat's Official Website [online]. Retrieved from: http://ec.europa.eu/eurostat [Accessed 12 March 2018].

Forsythe P.J., 2010. Office Buildings - the importance of 'make-good' fitout and recurring embodied energy. Proceedings of the CIB SB10 Conference. Wellington, New Zealand.

Forsythe, P. and Wilkinson, S.J., 2014. Measuring office fit-out changes to determine recurring embodied energy in building life cycle assessment. Emerald Insight, 33 (3,4): 262-274. DOI: 10.1108/F-08-2013-0065

Globechain, 2018. Globechain's Official Website [online]. Retrieved from: https://www.globechain.co.uk/ [Accessed 24 August 2018].

Hardie, M., Khan, S. and Miller, G., 2011. Waste minimisation in office refurbishment projects: an Australian perspective. Open Waste Management Journal, 4: 21-27. DOI: 10.2174/1876400201104010021

ISF (Institute for Sustainable Futures), 2014. Market research: Tenancy fitout material procurement attitude and practices [online]. University of Technology Sidney. Retrieved from:

http://www.sydneybetterbuildings.com.au/assets/2014/07/Final-Market-Research-Tenancy-Fitout-MaterialProcurement-Attitudes-Practice.pdf [Accessed 12 December 2015].

Lee, R., 1987. Building Maintenance Management. $3^{\text {rd }}$ ed. Oxford, UK: BSP Professional. In: Mansfield, J., What's in a name? Complexities in the definition of "refurbishment". Property Management, 20 (1): 23.30. DOI: $10.1108 / 02637470210418942$ 
Mcdonough, W. and Braungart, M., 2002. Cradle to Cradle: Remaking the Way We Make Things. New York, USA: North Point Press.

Mobius-reemploi, 2018. Mobius-Reemploi's Official Website [online]. Retrieved from: http://mobius-reemploi.fr/ [Accessed 24 August 2018].

RICS (Royal Institution of Chartered Surveyors), 1973. The Rehabilitation of Homes and Other Buildings. In: Mansfield, J., What's in a name? Complexities in the definition of "refurbishment". Property Management, 20 (1): 23-30. DOI: $10.1108 / 02637470210418942$

RICS (Royal Institution of Chartered Surveyors), 1997. Refurbishment in the Office Sector 1997/8: The Connaught Report. In: J. Mansfield, What's in a name? Complexities in the definition of "refurbishment". Property Management, 20 (1): 23.30. DOI: 10.1108/02637470210418942

RICS (Royal Institution of Chartered Surveyors), 2018. SKA Rating Official Website [online]. Retrieved from: http://www.rics.org/uk/knowledge/ska-rating-/ [Accessed 21 August 2018].

RotorDC, 2018. Rotor Deconstruction's Official Website [online]. Retrieved from: https://rotordc.com/ [Accessed 24 August 2018]

Roussac, C., Mcgee, C. and Milne, G., 2008. Changing the culture of commercial buildings in Australia: the role of green leases. Proceedings of the 2008 World Sustainable Building Conference, 1876-1881.

Seely, A., 2009. Landfill tax: introduction \& early history [online]. House of Commons Library. Retrieved from: http://researchbriefings.parliament.uk/ResearchBriefing/Summary/SN00237 [Accessed 15 October 2016].

Tucker, S.N. and Treloar, G.J., 1994. Embodied energy in the construction and refurbishment of building. Proceedings of CIB International conference on Buildings and the Environment 1994. Garston, UK.

UK Government, 2018. Waste acceptance at landfills - Guidance on waste acceptance procedures and criteria [online]. Retrieved from:

https://www.gov.uk/government/uploads/system/uploads/attachment_data/file/296422/geho1110btew-e-e.pdf [Accessed 27 March 2018].

USGBC (US Green Building Council), 2018. LEED's (Leader in Energy and Environmental Design) Official Website [online]. Retrieved from: https://new.usgbc.org/leed [Accessed 21 August 2018].

Warpit, 2018. Warpit's Official Website [online]. Retrieved from: https://www.warp-it.co.uk/ [Accessed 24 August 2018].

Zabalza, I., Aranda, A. and Scarpellini, S., 2009. Life cycle assessment in buildings: state-of-the-art and simplified LCA methodology as a complement for building certification. Building and Environment, 44 (12): 2510-2520. 